\title{
Job Satisfaction Level for Proactive Management: A Case Study at Jovay Mine Ghana Limited
}

\author{
James Obiri-Yeboah \\ Metallurgy Department, Akroma Gold Company Limited, Nkawkaw, Ghana \\ Email address: \\ obirik@yahoo.co.uk \\ To cite this article: \\ James Obiri-Yeboah. Job Satisfaction Level for Proactive Management: A Case Study at Jovay Mine Ghana Limited. Journal of Human \\ Resource Management. Special Issue: Job Satisfaction Level for Proactive Management. Vol. 8, No. 2, 2020, pp. 76-84. \\ doi: $10.11648 /$ j.jhrm.201200802.15
}

Received: February 24, 2020; Accepted: March 9, 2020; Published: April 1, 2020

\begin{abstract}
This study review the important of job satisfaction facets in production arena of Jovay Gold Company limited, Process Plant. It aims at rectifying the various shortfalls of using worst case scenario to enhance improvement. Clearly, the paper developed a model or steps for prioritizing the various job satisfaction parameters to enhance the focus of management control on the critical overall employee job satisfaction dependency factor that will maximize profit. The lack of systemic priority model for job satisfaction parameters in the company is a gap which needed to be eradicated to overcome the dilemma situation of predicting which job satisfaction parameters (factor) to handle at a given time. The paper provides rout for evaluating given data to form priority ranking for job satisfaction parameters. The priority model staircase of step 1, 2, 3, 4, 5 and 6 provided by this research corresponds to data collation, data analysis into job satisfaction score, summarizing of scores into overall percentage scores, trendline options analysis of data, selection of best fit trendline option by comparing the of respective R2 values and ranking R2 of best fit trendline according to their relationship strength option. Additionally, equation for the best fit trendline options are developed to provide the arena or model for predicting the probable level for future job satisfaction focus for managerial key performance indications. The total samples of 60 were subjected to statistical evaluation, a standard of $8.71 \%$ and error of $\pm 2.21 \%( \pm 0.0221)$ were obtained for the given data.
\end{abstract}

Keywords: Job Satisfaction, Facet, Dilemma, Priority, Ambivalence and Ranking

\section{Introduction}

Job satisfaction governs the mark to which different employees become content with their job. Generally, employees who are satisfied with their jobs show high commitment and lower intention to abandon that job. Also, job satisfaction characterizes a blend of optimistic or pessimistic frame of mind that workers have towards their work [1, 2]. Cook [3], shows researchers' with the conclusion that, worker satisfaction results in better employee retention. Clearly, job satisfaction definitions express the combination of emotional, physiological and environmental settings that affect a person to honorably express gratification of his or her work [4, 5]. Notably, it makes good business sense to frequently check in on the happiness of employees in the various departments of company. This is because studies have shown that there is a positive link between job satisfaction and productivity, financial results, and customer satisfaction. It is therefore important to find out the job satisfaction levels of employees and what should be changed to ensure expected outcome $[1,6]$. Therefore, the framework of this research covers evaluation of the already established quarterly employee job satisfaction records at the Human resource department of the company to formulate a priority model that will enhance proactive management in a given production limited resources. The current dependency of managing employee job satisfaction on periodic assessment of job satisfaction, lacks the needed proactive instinct to overcome the potential futuristic adverse effect associated with job satisfaction parameters (factors).

Consequently, this paper is to close the lack of systemic priority model gap existing in the company as a solution to eradicate the dilemma situation of predicting which job satisfaction parameters (factor) to handle at given time in order to again optimum employee job satisfaction results. The paper aims at developing a model or steps for 
prioritizing the various job satisfaction parameters to enhance the focus of management control on the critical overall employee job satisfaction dependency factor that will maximize profit. Additionally, the goal of this research is to formulate a priority model for proactive evaluation of employee job satisfaction levels at Jovay mine Ghana Limited with 2018 gold production year performance of $2.10 \%$ below budget and $3.20 \%$ employee turnover [7]. This will help management to successfully address any adverse effect that might result from a given job satisfaction facet (factor) at right times.

\section{Job Satisfaction Evaluation Jovay Mine Ghana Limited}

Imperatively, this research is to formulate a priority model for proactive evaluation of employee job satisfaction level at Jovay mine Ghana Limited to resolve the 2018 gold production year performance of $2.10 \%$ below budget and $3.20 \%$ employee turnover [7]. This information will help the company in developing management strategies to influence employee job satisfaction which may lead to increase in productivity, revenue and employee retention.

Technically, from Human Resource Report [7] and Spector [8], Jovay mine Ghana Limited Jovay Mine Ghana Limited uses the Job Satisfaction Survey (JSS) questionnaire developed by Paul E. Spector of the University of South Florida. It is a 36 item with nine facet scale to evaluate employee approaches about his or her job. Each facet is measured with four items and the overall total score is calculated from all items. A rating scale layout is used with ranging from "strongly disagree" to "strongly agree". Every item has six choices. The nine facets are pay, promotion, supervision, fringe benefits, contingent rewards, operating procedures, coworkers, nature of work, and communication. A score of six (6) indicates strongest agreement and a score of one (1) depicts strongest disagreement on a worded item to provide a meaningful combination. The other notation indications are 2, 3, 4 and 5 which correspond to moderate disagreement, slight disagreement, slight agreement and moderate agreement respectively.

Furthermore, the mean scores of job satisfaction survey facets were estimated after reversal of negatively worded items. The respondents mean score value of greater than or equal to 4 for the facet item numbers represent satisfaction whiles less than or equal to 3 represent dissatisfaction. Also, mean score values between 3 and 4 signify ambivalence or uncertainty. Furthermore, the summation of mean scores are expressed in percentages with the three overall job satisfaction categories of less than $50 \%, 50 \%$ and greater than $50 \%$ corresponding to indications of dissatisfaction (i.e. low job satisfaction), ambivalence or uncertainty and satisfaction (high job satisfaction) [8].

Clearly, this job satisfaction assessment gives indication for management to focus on worst case job satisfaction survey facets at Jovay mine Ghana Limited which has a shortfall of not meeting the overall employee job satisfaction dependency factors. The importance of job satisfaction survey estimates at Jovay mine Ghana Limited, hinge on its effect on the employee turnover and profit margin of production. Since the adverse effects of the employee job satisfaction at Jovay mine Ghana Limited occurred before the assessments notification, management deem it better to have a complimentary evaluation system or model which is proactive to overcome any future adverse consequences.

\section{Material and Method Used}

Essentially, the deficiency of current job satisfaction level evaluation at Jovay Mine Ghana limited is a recipe for production and revenue deficits. Therefore, the various percentage levels of job satisfaction facets of 2018 and 2019 quarterly job satisfaction records as at June 2019 month end from the Human resource department were studied to evaluate their respective effect on their overall corresponding average percentage job satisfaction levels. Quantitative evaluations of pay, promotion, supervision, fringe benefits, contingent rewards, operating procedures, coworkers, nature of work, and communication were obtained to enhance practical conclusions. According to McGregor [9], job satisfaction percentage evaluation enhances the focus of management on the needed requirement for improvement of employees' working conditions. Again, Böckerman and Ilmakunnas [10], develop a relationship model between job satisfaction and productivity by using regression analysis method. Imperatively, Sharma [11] and Saunders et. al [12], affirmed the use of trend line options to select the best trend line for predicting values of a dependent variable from given values of one or more independent variable. From the facets (pay, promotion, supervision, fringe benefits, contingent rewards, operating procedures, coworkers, nature of work, and communication) and their corresponding percentage levels of job satisfaction, call for the use of statistical approach of trend line options analysis as the appropriate model method for prioritizing factors of employee job satisfaction levels to enhance proactive management evaluations.

\section{Results and Discussions}

Basically, the inadequacy of information on priority model existing in the company is a recipe for the existing dilemma situation of predicting which job satisfaction parameter condition which management should be focus on, at the time of need is the gaps that this study seeks out to examine. Therefore, the purpose of this study is to close the information gaps in the existing literature on prioritizing factors of employee job satisfaction level for effective and proactive management. From results of quarterly employee job satisfaction analysis by the Human Resource department of the Jovay mine Ghana Limited, quantitative analysis was done to establish a proactive model. Tables 1, 2, 3, 4, 5 and 6 were utilized to obtain the require model development. By the use of the JSS questioner, dissatisfaction and Satisfaction of respondents are deduced to evaluate the various respective 
percentages for the job satisfaction facet (Scale) of pay, promotion, supervision, fringe benefits, contingent rewards, operating procedures, coworkers, nature of work and communication. Consequently, two overall average percentage satisfaction scores for dissatisfaction and satisfaction are deduced by using the total respondents as reference point figure. These two scores represent overall dissatisfaction and satisfaction performance score for the given quarter of the year.

Table 7 shows the summary of the quarterly job satisfaction levels for year 1 and year 2 with the figure 1 showing corresponding graph. This is done to give management the facet to focus on, in order to generate the needed job satisfaction among employees. The criteria for selection is based on the bar chart shows the lowest or the worst case scenario job satisfaction on the graph.

Table 1. Year 1 Quarter 1 Job satisfaction report.

\begin{tabular}{|c|c|c|c|c|c|}
\hline \multirow{2}{*}{ Scale } & \multicolumn{2}{|l|}{ Average score } & \multirow{2}{*}{ Total } & \multicolumn{2}{|l|}{ Percentages } \\
\hline & Dissatisfaction & Satisfaction & & Dissatisfaction & Satisfaction \\
\hline Pay & 117.4 & 122.7 & 240.1 & 48.9 & 51.1 \\
\hline Promotion & 100.4 & 151.3 & 251.7 & 39.9 & 60.1 \\
\hline Supervision & 134.5 & 174.3 & 308.8 & 43.6 & 56.4 \\
\hline Fringe Benefits & 109.0 & 110.0 & 219.0 & 49.8 & 50.2 \\
\hline Contingent Rewards & 144.0 & 101.5 & 245.5 & 58.7 & 41.3 \\
\hline Operating Procedures & 159.8 & 99.7 & 259.5 & 61.6 & 38.4 \\
\hline Nature of Work & 105.1 & 200.3 & 305.3 & 34.4 & 65.6 \\
\hline Communication & 180.3 & 106.2 & 286.5 & 62.9 & 37.1 \\
\hline \multicolumn{4}{|c|}{ Overall Average Percentage Satisfaction Score } & 49.6 & 50.4 \\
\hline
\end{tabular}

Table 2. Year 1 Quarter 2 Job satisfaction report.

\begin{tabular}{|c|c|c|c|c|c|}
\hline \multirow{2}{*}{ Scale } & \multicolumn{2}{|l|}{ Average score } & \multirow{2}{*}{ Total } & \multicolumn{2}{|l|}{ Percentages } \\
\hline & Dissatisfaction & Satisfaction & & Dissatisfaction & Satisfaction \\
\hline Pay & 139.8 & 119.7 & 259.4 & 53.9 & 46.1 \\
\hline Promotion & 104.8 & 161.3 & 266.1 & 39.4 & 60.6 \\
\hline Supervision & 138.7 & 124.8 & 263.4 & 52.6 & 47.4 \\
\hline Fringe Benefits & 142.8 & 103.8 & 246.5 & 57.9 & 42.1 \\
\hline Contingent Rewards & 159.8 & 103.2 & 263.0 & 60.8 & 39.2 \\
\hline Operating Procedures & 162.4 & 93.8 & 256.2 & 63.4 & 36.6 \\
\hline Nature of Work & 110.9 & 166.7 & 277.6 & 40.0 & 60.0 \\
\hline Communication & 180.3 & 106.2 & 286.5 & 62.9 & 37.1 \\
\hline \multicolumn{4}{|c|}{ Overall Average Percentage Satisfaction Score } & 53.0 & 47.0 \\
\hline
\end{tabular}

Table 3. Year 1 Quarter 3 Job satisfaction report.

\begin{tabular}{|c|c|c|c|c|c|}
\hline \multirow{2}{*}{ Scale } & \multicolumn{2}{|l|}{ Average score } & \multirow{2}{*}{ Total } & \multicolumn{2}{|l|}{ Percentages } \\
\hline & Dissatisfaction & Satisfaction & & Dissatisfaction & Satisfaction \\
\hline Pay & 120.0 & 147.7 & 267.7 & 44.8 & 55.2 \\
\hline Promotion & 93.6 & 232.3 & 325.9 & 28.7 & 71.3 \\
\hline Supervision & 110.6 & 110.8 & 221.4 & 49.9 & 50.1 \\
\hline Fringe Benefits & 125.5 & 167.0 & 292.5 & 42.9 & 57.1 \\
\hline Contingent Rewards & 121.3 & 111.0 & 232.3 & 52.2 & 47.8 \\
\hline Operating Procedures & 121.2 & 117.8 & 238.9 & 50.7 & 49.3 \\
\hline Nature of Work & 84.2 & 167.4 & 251.6 & 33.5 & 66.5 \\
\hline Communication & 125.5 & 148.4 & 273.9 & 45.8 & 54.2 \\
\hline \multicolumn{4}{|c|}{ Overall Average Percentage Satisfaction Score } & 44.2 & 55.8 \\
\hline
\end{tabular}

Table 4. Year 1 Quarter 4 Job satisfaction report.

\begin{tabular}{|c|c|c|c|c|c|}
\hline \multirow{2}{*}{ Scale } & \multicolumn{2}{|l|}{ Average score } & \multirow{2}{*}{ Total } & \multicolumn{2}{|l|}{ Percentages } \\
\hline & Dissatisfaction & Satisfaction & & Dissatisfaction & Satisfaction \\
\hline Pay & 136.3 & 104.7 & 240.9 & 56.6 & 43.4 \\
\hline Promotion & 100.7 & 123.2 & 223.8 & 45.0 & 55.0 \\
\hline Supervision & 137.7 & 109.9 & 247.6 & 55.6 & 44.4 \\
\hline Fringe Benefits & 140.0 & 97.9 & 237.9 & 58.8 & 41.2 \\
\hline Contingent Rewards & 171.4 & 93.2 & 264.6 & 64.8 & 35.2 \\
\hline Operating Procedures & 160.9 & 99.5 & 260.4 & 61.8 & 38.2 \\
\hline Nature of Work & 112.2 & 124.5 & 236.7 & 47.4 & 52.6 \\
\hline Communication & 141.1 & 107.5 & 248.6 & 56.8 & 43.2 \\
\hline \multicolumn{4}{|c|}{ Overall Average Percentage Satisfaction Score } & 55.9 & 44.1 \\
\hline
\end{tabular}


Table 5. Year 2 Quarter 1 Job satisfaction report.

\begin{tabular}{|c|c|c|c|c|c|}
\hline \multirow{2}{*}{ Scale } & \multicolumn{2}{|l|}{ Average score } & \multirow{2}{*}{ Total } & \multicolumn{2}{|l|}{ Percentages } \\
\hline & Dissatisfaction & Satisfaction & & Dissatisfaction & Satisfaction \\
\hline Pay & 117.4 & 122.7 & 240.1 & 48.9 & 51.1 \\
\hline Promotion & 100.4 & 151.3 & 251.7 & 39.9 & 60.1 \\
\hline Supervision & 134.5 & 174.3 & 308.8 & 43.6 & 56.4 \\
\hline Fringe Benefits & 109.0 & 110.0 & 219.0 & 49.8 & 50.2 \\
\hline Contingent Rewards & 144.0 & 101.5 & 245.5 & 58.7 & 41.3 \\
\hline Operating Procedures & 159.8 & 99.7 & 259.5 & 61.6 & 38.4 \\
\hline Coworkers & 150.2 & 170.6 & 320.8 & 46.8 & 53.2 \\
\hline Nature of Work & 105.1 & 200.3 & 305.3 & 34.4 & 65.6 \\
\hline Communication & 180.3 & 106.2 & 286.5 & 62.9 & 37.1 \\
\hline \multicolumn{3}{|c|}{ Overall Average Percentage Satisfaction Score } & & 49.6 & 50.4 \\
\hline
\end{tabular}

Table 6. Year 2 Quarter 2 Job satisfaction report.

\begin{tabular}{llllll}
\hline \multirow{2}{*}{ Scale } & Average score & & \multirow{2}{*}{ Total } & & Percentages \\
\cline { 2 - 3 } \cline { 5 - 6 } & Dissatisfaction & Satisfaction & & Dissatisfaction & Satisfaction \\
\hline Pay & 136.7 & 145.8 & 282.4 & 48.4 & 51.6 \\
Promotion & 98.8 & 173.8 & 272.5 & 36.2 & 63.8 \\
Supervision & 133.6 & 91.4 & 225.0 & 59.4 & 40.6 \\
Fringe Benefits & 145.9 & 149.8 & 295.8 & 49.3 & 50.7 \\
Contingent Rewards & 174.1 & 101.7 & 275.8 & 63.1 & 36.9 \\
Operating Procedures & 159.5 & 104.8 & 264.3 & 60.4 & 39.6 \\
Coworkers & 122.6 & 95.9 & 218.5 & 56.1 & 43.9 \\
Nature of Work & 106.9 & 122.3 & 229.3 & 46.6 & 53.4 \\
Communication & 145.6 & 98.1 & 243.7 & 59.7 & 40.3 \\
Overall Average Percentage Satisfaction Score & & & 53.3 & 46.7 \\
\hline
\end{tabular}

Table 7. Job satisfaction factors analysis.

\begin{tabular}{lllllll}
\hline Year & $\mathbf{1}$ & $\mathbf{1}$ & $\mathbf{1}$ & $\mathbf{1}$ & $\mathbf{2}$ & $\mathbf{2}$ \\
\hline Quarter & $\mathbf{1}$ & $\mathbf{2}$ & $\mathbf{3}$ & $\mathbf{4}$ & $\mathbf{1}$ & $\mathbf{2}$ \\
\hline Pay & 51.1 & 46.1 & 55.2 & 43.4 & 51.1 & 51.6 \\
Promotion & 60.1 & 60.6 & 71.3 & 55 & 60.1 & 63.8 \\
Supervision & 56.4 & 47.4 & 50.1 & 44.4 & 56.4 & 40.6 \\
Fringe Benefits & 50.2 & 42.1 & 57.1 & 41.2 & 50.2 & 50.7 \\
Contingent Rewards & 41.3 & 39.2 & 47.8 & 35.2 & 41.3 & 36.9 \\
Operating Procedures & 38.4 & 36.6 & 49.3 & 38.2 & 38.4 & 39.6 \\
Coworkers & 53.2 & 53.8 & 50.6 & 43.9 & 53.2 & 43.9 \\
Nature of Work & 65.6 & 60 & 66.5 & 52.6 & 65.6 & 53.4 \\
Communication & 37.1 & 37.1 & 54.2 & 43.2 & 37.1 & 40.3 \\
Overall Average Satisfaction & 50.4 & 47 & 55.8 & 44.1 & 50.4 & 46.7 \\
\hline
\end{tabular}

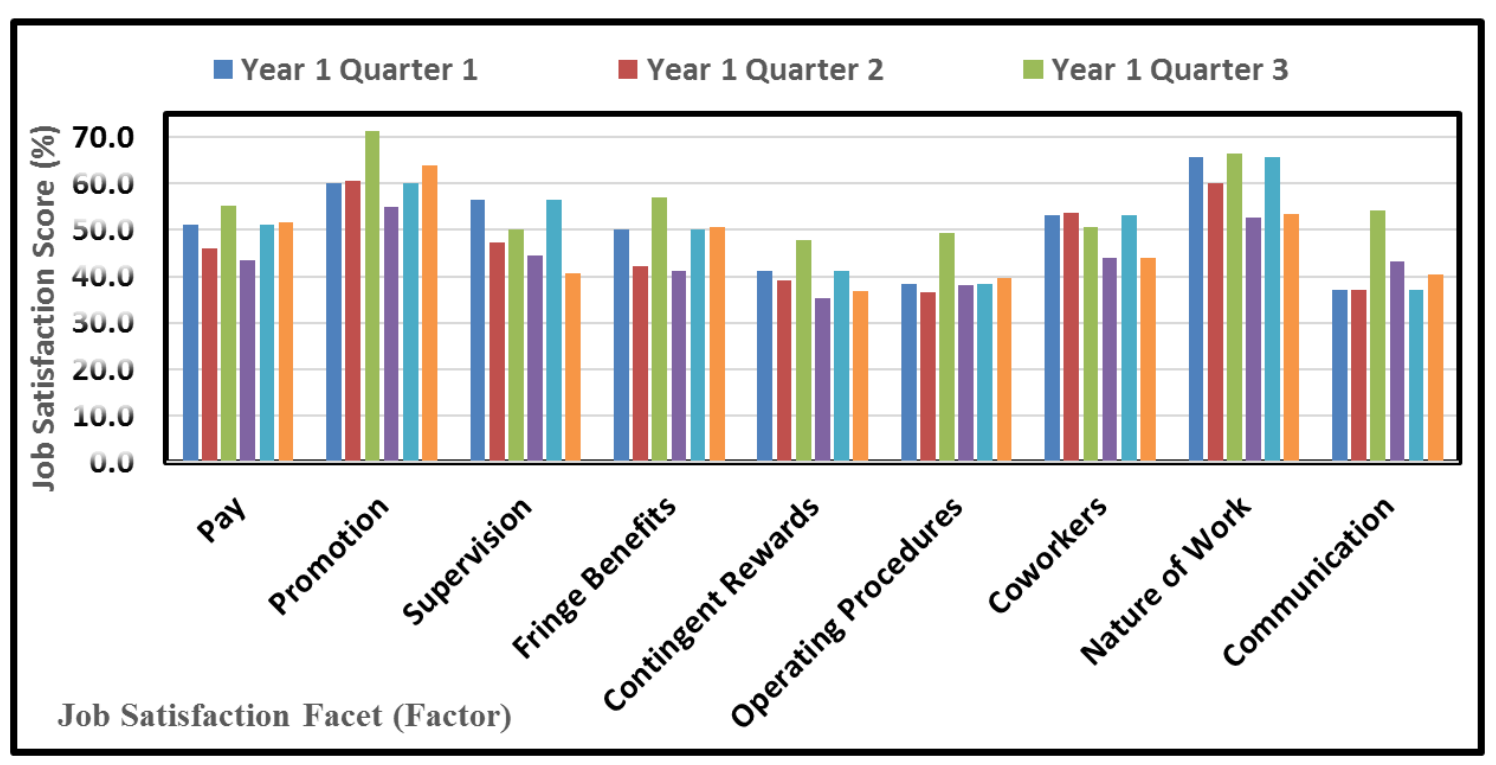

Figure 1. Current used quarterly job satisfaction analysis at Jovay Mine Limited. 
Figure 1 shows the currently used graph for selecting the job satisfaction facet situation that need to be addressed to enhance employee job satisfaction with aim of achieving optimum production. Per the currently used bar chart graph system in place, year 1 quarter 3, promotion as the highest facet that induced employee job satisfaction whiles year 1, quarter 4 , contingency rewards shows the lowest score point of $35.2 \%$ as critical level that require immediate action. That is contingency rewards shows the worst case scenario which point to the need for immediate remedial measures to prevent any unforeseen agitations by employees. Clearly, this way of resolving adverse factors affecting employee job satisfaction has higher dependency on past occurrence which put always put management into reactive mode and may have negligible effect on the employees' need of the given point in time.

However, this paper introduces a principle which subject all the faces (pay, promotion, supervision, fringe benefits, contingent rewards, operating procedures, coworkers, nature of work and communication) to trendline options analysis by the use Microsoft excel software evaluations. Each facet quarterly job satisfaction scores for year 1 and 2 were made dependent variables whiles their respective overall job satisfaction scores were considered as independent variables. The $\mathrm{R}^{2}$ values for five trendline options (i.e. exponential, linear, logarithmic, polynomial and power) for each facet were evaluated to show the strength of relationship between the given variables [11]. Figures 2, 3, 4, 5 and 6 show the $\mathrm{R}^{2}$ values of various trendline options for Pay job satisfaction facet and this was repeated for all the facets to obtain their $\mathrm{R}^{2}$ values as depicted on table 8 . The highlighted figures on table 8 , show the polynomial trend options as the best fit graphs by virtue of their $\mathrm{R}^{2}$ values being highest as compared to their corresponding trendline options.

Table 8. Job satisfaction factors trendline analysis.

\begin{tabular}{|c|c|c|c|c|c|}
\hline \multirow{2}{*}{$\begin{array}{l}\text { Job Satisfaction Factor } \\
\text { or facet (Scale) }\end{array}$} & \multicolumn{5}{|c|}{$\mathbf{R}^{2}$ for Trendline Options } \\
\hline & Exponential & Linear & Logarithmic & Polynomial & Power \\
\hline Pay & 0.7568 & 0.7457 & 0.7300 & 0.8092 & 0.7433 \\
\hline Promotion & 0.6593 & 0.6713 & 0.6658 & 0.6759 & 0.6566 \\
\hline Supervision & 0.3344 & 0.3135 & 0.3246 & 0.3742 & 0.3446 \\
\hline Fringe Benefits & 0.7651 & 0.7635 & 0.7409 & 0.8213 & 0.7455 \\
\hline Contingent Rewards & 0.9688 & 0.9744 & 0.9740 & 0.9749 & 0.9722 \\
\hline Operating Procedures & 0.6033 & 0.6374 & 0.6318 & 0.6499 & 0.5980 \\
\hline Nature of Work & 0.7578 & 0.7355 & 0.7246 & 0.8106 & 0.7473 \\
\hline Communication & 0.2852 & 0.3199 & 0.2769 & 0.8964 & 0.2439 \\
\hline
\end{tabular}

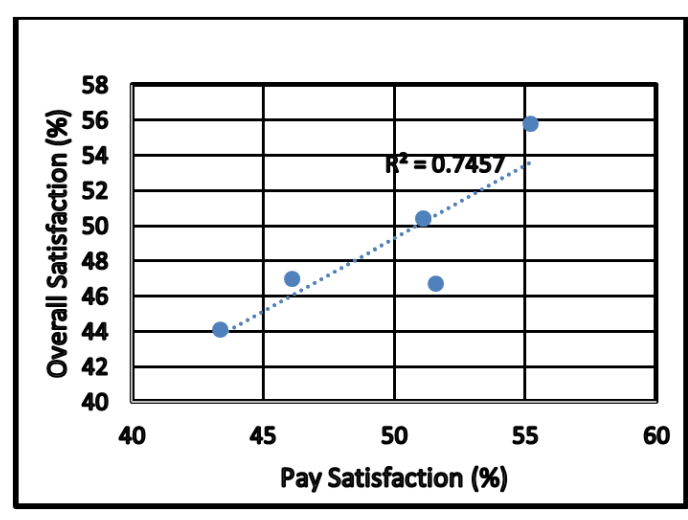

Figure 2. Pay facet linear trendline option $R^{2}$ values.

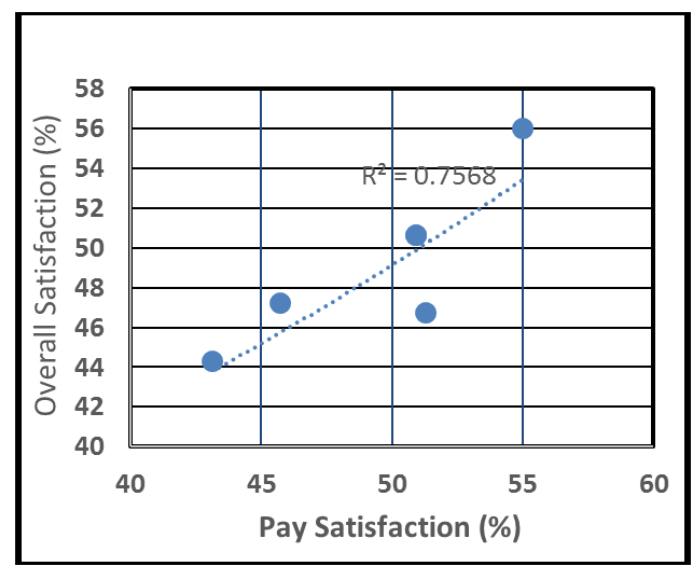

Figure 3. Pay facet Exponential trendline option $R^{2}$ values.

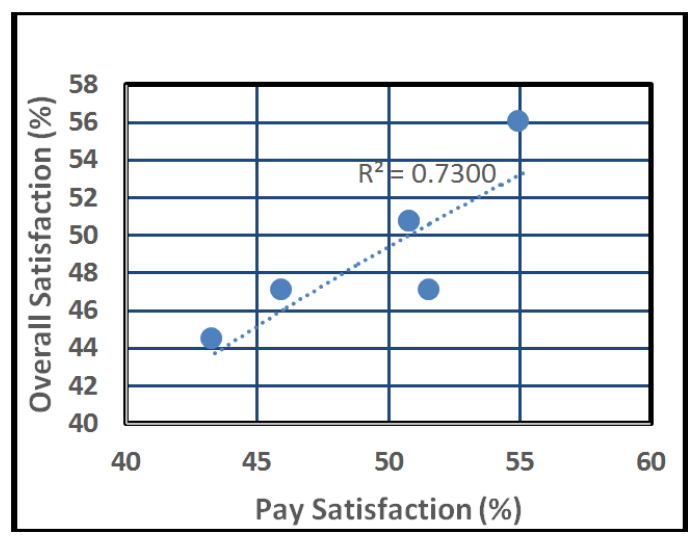

Figure 4. Pay facet Logarithmic trendline option $R^{2}$ values.

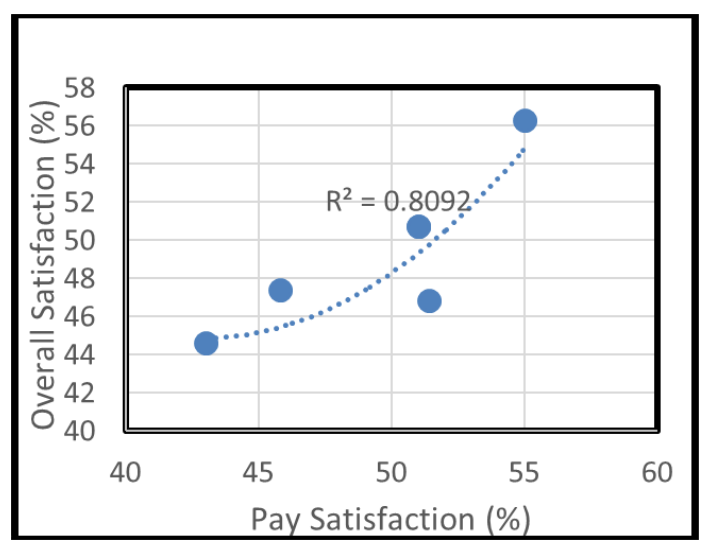

Figure 5. Pay facet Polynomial trendline option $R^{2}$ values. 


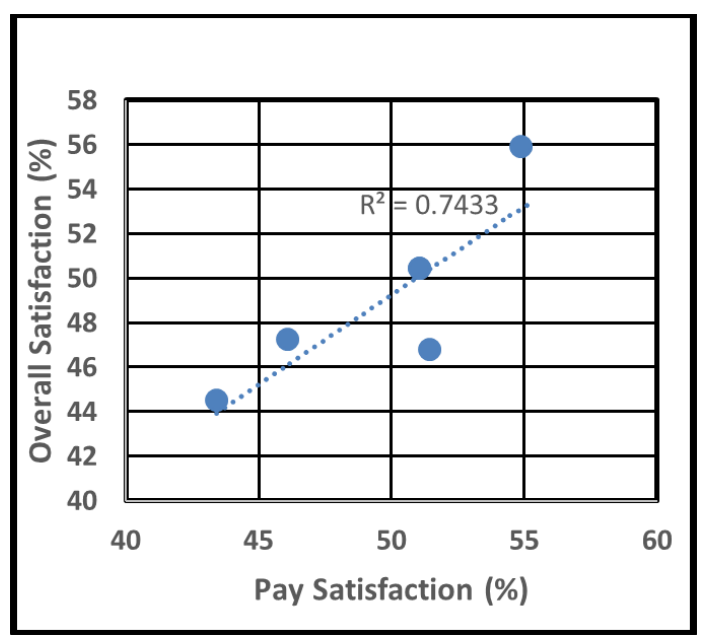

Figure 6. Pay facet Power trendline option $R^{2}$ values.

From table 8 gives ranges $\mathrm{R}^{2}$ values for exponential, linear, logarithmic, polynomial and power trendline options as given by the Microsoft excel program. The best trend lines of the description for analyzing the given job satisfaction facets or factors are the polynomial graphs. This is due to the values of polynomial $\mathrm{R}^{2}$ from the lowest value of 0.3742 to the highest of 0.9749 as highlighted show the highest range $\mathrm{R}^{2}$ values of all the job satisfaction facets (i.e. Pay, Promotion, Supervision, Fringe Benefits, Contingent Rewards, Operating Procedures, Coworkers, Nature of Work and Communication). Figures 7, 8 and 9 show the best fit trend options under comparison. Hence the polynomial curves are selected for priority model ranking, the position or rank of each facet is based their corresponding $\mathrm{R}^{2}$ value which expresses the dependency of the overall average job satisfaction value on the given facet. Table 9 shows the rank table for the polynomial curves. From table 9, job satisfaction facets of Contingent Rewards, Coworkers, Communication, Fringe Benefits, Nature of Work, Pay, Promotion, Operating Procedures and Supervision are ranked as $1^{\text {st }}, 2^{\text {nd }}, 3^{\text {rd }}, 4^{\text {th }}, 5^{\text {th }}, 6^{\text {th }}$, $7^{\text {th }}, 8^{\text {th }}$ and $9^{\text {th }}$ respectively. This priority rankings is supposed to help management to address the facet needs of a given time.

Table 9. Job satisfaction factors Priority Ranks.

\begin{tabular}{|c|c|c|}
\hline Job Satisfaction Factor & $\mathrm{R}^{2}$ of the Polynomial curve & Priority Rank \\
\hline Contingent Rewards & 0.9749 & $1^{\mathrm{st}}$ \\
\hline Coworkers & 0.9475 & $2^{\text {nd }}$ \\
\hline Communication & 0.8964 & $3^{\text {rd }}$ \\
\hline Nature of Work & 0.8106 & $5^{\text {th }}$ \\
\hline Pay & 0.8092 & $6^{\text {th }}$ \\
\hline Promotion & 0.6759 & $7^{\text {th }}$ \\
\hline Supervision & 0.3742 & $9^{\text {th }}$ \\
\hline
\end{tabular}

\subsection{Best Fit Trendline Option (Polynomial) Graphs for Job Satisfaction Factors}

Clearly, Access [13], pointed out that trendline options can be added to Microsoft graphs by choosing from the six different trends available with reference to the reliability of individual trend option. Trendline reliability is evaluated by comparing the $\mathrm{R}^{2}$ values of the all different trend options. The most reliable of trendline is based on the nearest of the $\mathrm{R}^{2}$ value to 1 (one) as per the Microsoft automatic calculation. By comparing the magnitude of $\mathrm{R}^{2}$ values of all the trendline options for the respective job satisfaction facets, the polynomial trendline options standout as the highest for each given facet. Figure 7 gives the graphical representation of the polynomial trendline options for Pay, Promotion and Supervision job satisfaction facets whiles figure 8 represents Fringe Benefits, Contingent Rewards and Operating Procedures satisfaction facets. Figure 9 represents Coworkers, Nature of Work and Communication job satisfaction facets.

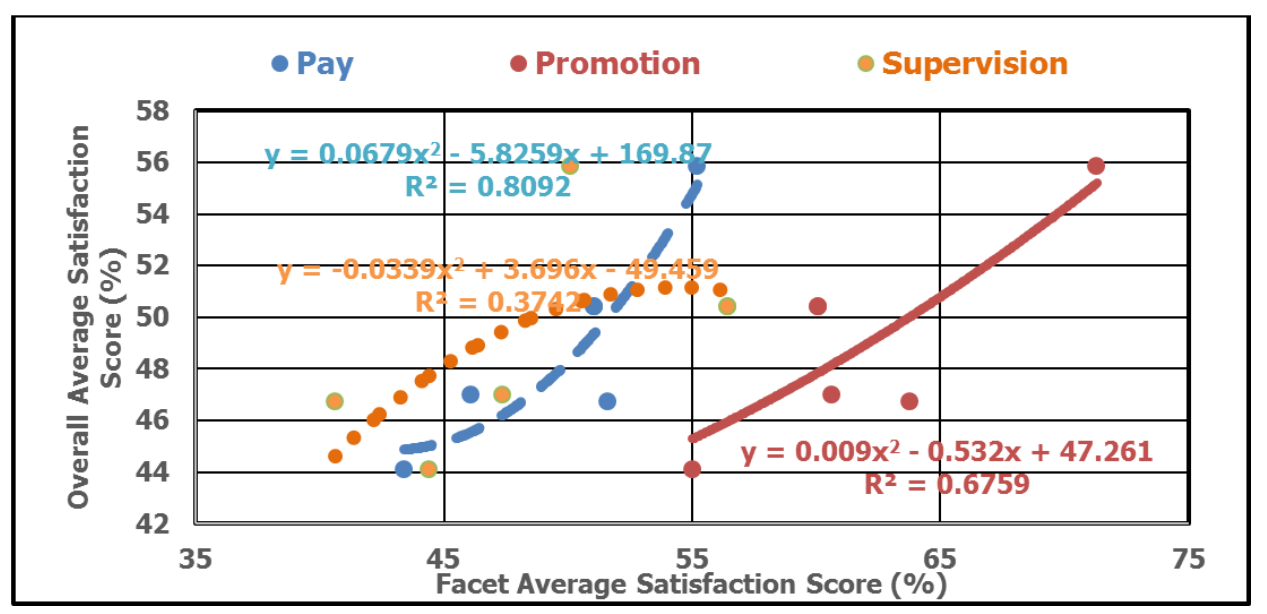

Figure 7. Graph for Pay, Promotion and Supervision satisfaction Facets. 


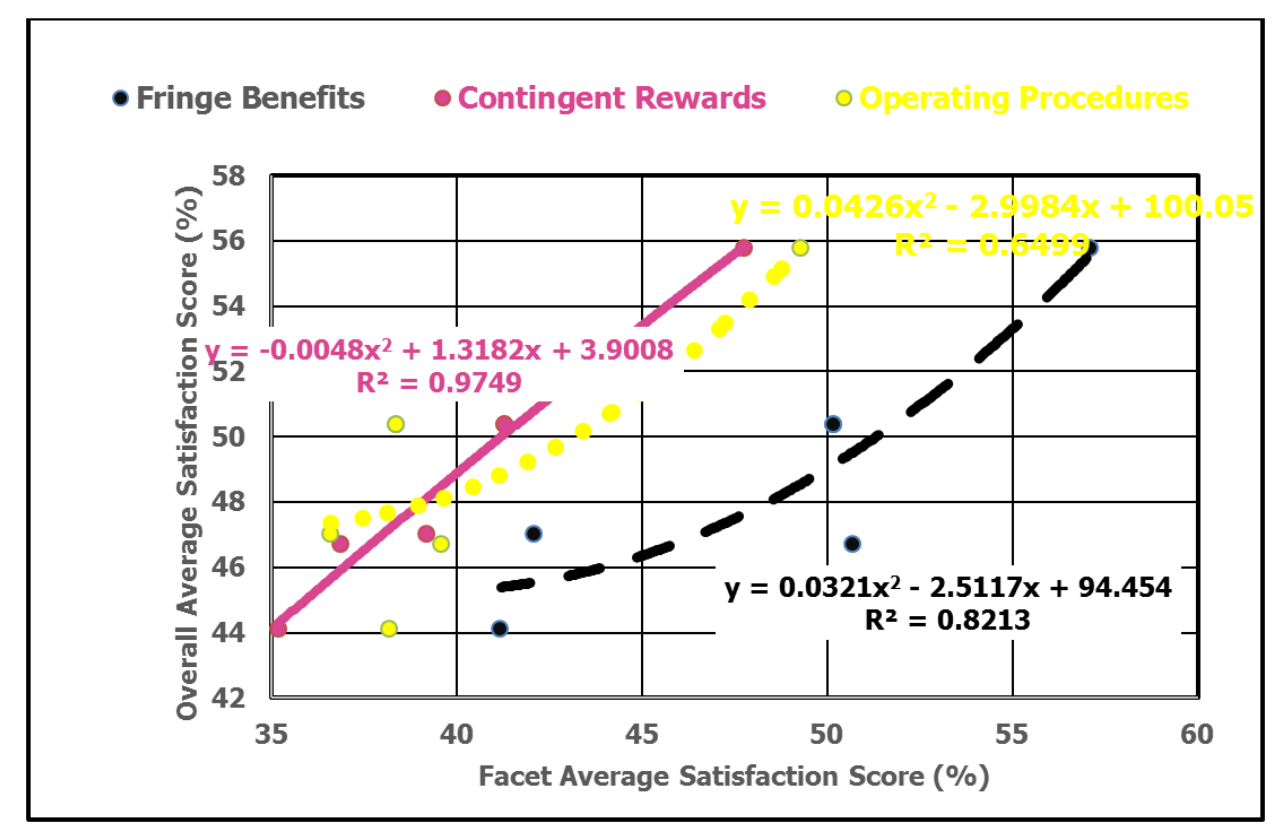

Figure 8. Graph for Fringe Benefits, Contingent Rewards and Operating Procedures satisfaction facets.

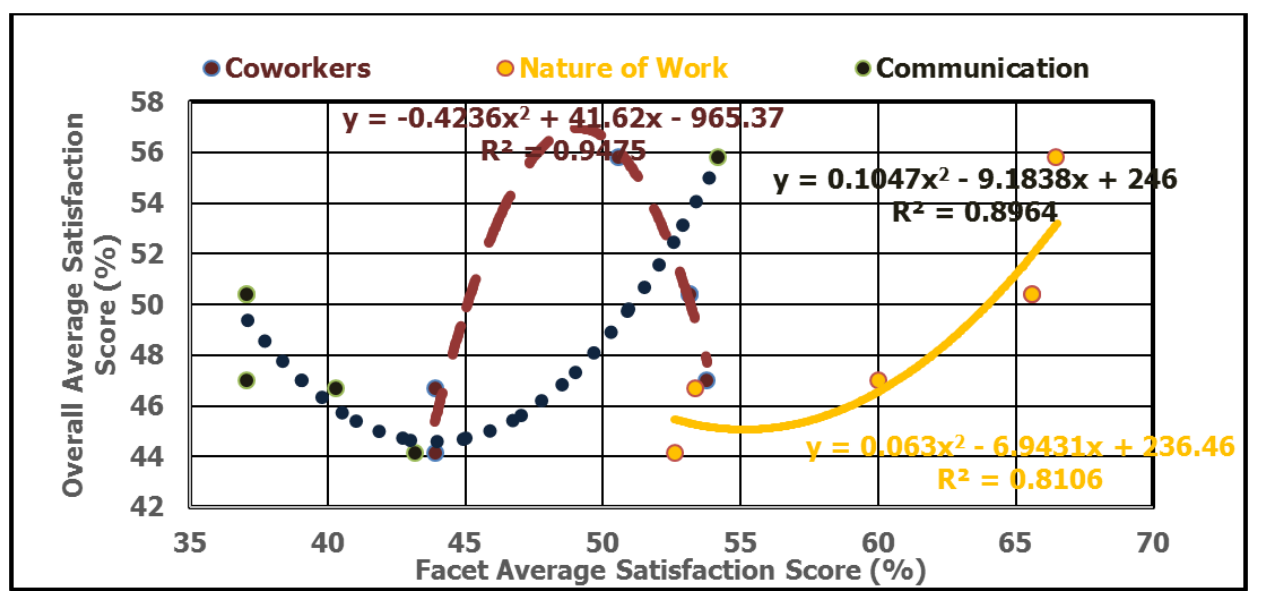

Figure 9. Graph for Coworkers, Nature of Work and Communication satisfaction facets.

From the best fit trendline options (i.e. figures 7 to 8 ), the polynomial equations can be extrapolated to predict a probably and tentative future overall average job satisfaction by assuming a given facet score. From Joeu, [14], the prediction out polynomial graph can only be described as being probably and tentative due the significant deviation of the curves from the ' $x$ ' values of the graphs. However these polynomial graphs can be best used for interpolation with prevailing ' $x$ ' values under evaluation. From figure 7, pay, promotion and supervision facets have $\mathrm{y}=0.0679 \mathrm{x}^{2}$ $5.8259 \mathrm{x}+169.87, \mathrm{y}=0.009 \mathrm{x}^{2}-0.532 \mathrm{x}+47.261$ and $\mathrm{y}=-$ $0.0339 x^{2}+3.696 x-49.459$ respectively. The facets of fringe benefits, contingency rewards and operating procedures are $\mathrm{y}$ $=0.0321 \mathrm{x}^{2}-2.5117 \mathrm{x}+94.454, \mathrm{y}=-0.0048 \mathrm{x}^{2}+1.3182 \mathrm{x}+$ 3.9008 and $\mathrm{y}=0.0426 \mathrm{x}^{2}-2.9984 \mathrm{x}+100.05$ respectively. Figure 4 shows the $\mathrm{y}=-0.4236 \mathrm{x}^{2}+41.62 \mathrm{x}-965.37, \mathrm{y}=$ $0.063 x^{2}-6.9431 x+236.46$ and $y=0.1047 x^{2}-9.1838 x+246$ as equations for Coworkers, Nature of Work and Communication satisfaction facets respectively. Predictably, the equation with the polynomial equation for contingency rewards as $\mathrm{y}=-0.0048 \mathrm{x}^{2}+1.3182 \mathrm{x}+3.9008$ can be used when one focuses on contingency rewards contingency rewards facet average satisfaction score, $\mathrm{x}$, of $68 \%$, then, corresponding probably and tentative deduction of overall average job satisfaction, $y$, would be $71.34 \%$. This can be repeated for all the various facets.

Tentatively, the equations of the figures 7,8 and 9 can be used to deduce, three categories (i.e. less than $50 \%, 50 \%$ and greater than $50 \%$ corresponding to indications of dissatisfaction, that is low job satisfaction, ambivalence or uncertainty and satisfaction which indicate high job satisfaction) of satisfaction [8]. Therefore, this method can probably help management to focus on the facet that will generate a higher employee job satisfaction with a plan or budget figure, as a driving key performance indicator. Alternatively, as per the description of Joeu [14], precision of extrapolation can be enhanced by using any of the other trend options with the $\mathrm{R}^{2}$ value (i.e. from table 8 ) which is second in magnitude to the polynomial $\mathrm{R}^{2}$ to overcome or control deviation associated with polynomial trends. From George et. 
al [15], when all the quarterly job satisfaction scores with total sample of 60 were subjected to statistical evaluation, a standard of $8.71 \%$ and error (i.e. by formula: Error $(\varepsilon)=$ $\mathrm{Z} \alpha . \sigma / \sqrt{ } \mathrm{n}$. where $\mathrm{Z} \alpha=1.96$ at $95 \%$ confidence interval, $\sigma=$ sample standard deviation, $\mathrm{n}=$ total number of sample) of $\pm 2.21 \%( \pm 0.0221)$ were obtained for the given data.

\subsection{Priority Model Staircase}

Figure 10 shows Priority model staircase diagram which describes step by step channel of providing the model. The first step (Step 1) relates to the process of obtaining employee job satisfaction scores. This includes the use of job satisfaction questionnaire to obtain results respondents. The second step (Step 2 on Priority model staircase diagram), relates analyzing the questionnaire results into percentage scores for the facets (i.e. Pay, Promotion, Supervision, Fringe Benefits, Contingent Rewards, Operating Procedures, Coworkers, Nature of Work and Communication). Third step (Step 3) involves summarizing all the facet scores to obtain overall job satisfaction score for a given period. The overall job satisfaction score is obtained by evaluating the mean (average) score for all the facets as a representative value for the given period. Step four (Step 4) deals with trendline options analysis to again $\mathrm{R}^{2}$ values for each option with respect to the various facets scores. This fourth step analysis is obtained by using Microsoft excel software trendline options principles. The fifth staircase (Step 5) involves selecting the best fit trendline option by comparing the respective $R^{2}$ values of the all trendline options for various facets. This is done comparing magnitude of $\mathrm{R}^{2}$ values which a direct function of strength of relationship between percentage facets scores and percentage overall job satisfaction scores. The final staircase (Step 6) deals with ranking of the $\mathrm{R}^{2}$ values of the best fit trendline option evaluated. This is done by comparing the $\mathrm{R} 2$ values of the selected best fit trendline by the arranging the facet according to magnitude of their $\mathrm{R}^{2}$ value.

\begin{tabular}{|l|}
\hline Step 6. Ranking $\mathrm{R}^{2}$ of Best fit trendline according their relationship strength option \\
\hline Step 5. Selection of Best fit trendline option by comparing the of respective $\mathrm{R}^{2}$ values \\
\hline Step 4. Trendline Options Analysis of Data \\
\hline Step 3. Summarizing of Scores into Overall percentage scores \\
\hline Step 2. Data Analysis into Job Satisfaction score \\
\hline Step 1. Data Collation from respondents by using a satisfied job satisfaction questionnaire \\
\hline
\end{tabular}

Figure 10. Shows Priority model staircase diagram.

\section{Conclusions}

Authentically, the use of bar chart graphs, based on worst case scenario of job satisfaction facet to resolve the overall job satisfaction problem is good but lack the potential of addressing dilemma of which facets in the overall job satisfaction of the employee. Hence, in order to overcome the said dilemma, there is the need to find out which facet to address at any given time. This point out the need to introduce priority model as complimentary assessment on the job satisfaction facets to resolve their shortfalls on the overall employee job satisfaction levels in a proactive management mode. Additionally, equation for the best fit trendline options are developed to provide the arena or model for predicting the probable level for future job satisfaction focus for managerial key performance indications. A priority model staircase of step 1, 2, 3, 4, 5 and 6 provided by this research corresponds to Data Collation from respondents by using a satisfied job satisfaction questionnaire, Data Analysis into Job Satisfaction score, Summarizing of Scores into Overall percentage scores, Trendline Options Analysis of Data, Selection of Best fit trendline option by comparing the of respective $\mathrm{R}^{2}$ values and Ranking $\mathrm{R}^{2}$ of Best fit trendline according their relationship strength option. Further research work is recommended to authenticate the probability levels of predictions results from the best fit equations application.

\section{References}

[1] Gorton N. (2017). Why you should discuss job satisfaction with your employees Retrieved from https://www.roberthalf.com.au/blog/employers/why-youshould-discuss-job-satisfaction-your-employees.

[2] Aziri B. (2011). Job satisfaction: a literature review. Management research and practice vol. 3 issue 4 PP: 78 . Retrieved from http://mrp.ase.ro/no34/f7.pdf.

[3] Cook, I. (2011) Does Job Satisfaction Lead to Better Results? Retrieved from http://psycnet.apa.org/index.cfm?fa=buy.optionToBuy\&id=20 11-20470-001.

[4] Robbins S. P. \& DeCenzo D. A. (2005). Fundamentals of management essential concepts and applications. Pearson Education, Inc., Upper Saddle River, New Jersey, 07458 U.S.A. 6- 386 pp. 
[5] Thiagaraj D. and Thangaswamy A. (2017). Theoretical Concept of Job Satisfaction -A Study. International Journal Of Research Granthaalayah, Vol. 5 (Iss. 6), June, 2017464 pp. Retrieve from http://granthaalayah.com/Articles/Vol5Iss6/56_IJRG17_A06_436 .pdf.

[6] Saari, L. M, and Judge, T. A. (2004). Employee attitudes and job satisfaction. Human Resource Management, Winter 2004, Vol. 43, No. 4, Pp. 398. Retrieved from https://www.utm.edu/staff/mikem/documents/jobsatisfaction.p df.

[7] Human Resource Report, (2018). Yearly Human Resource Report. Human Resource department of the Jovay Mine Ghana limited. 5pp.

[8] Spector, P. E. (1994). Job Satisfaction Survey. Retrieved from http://shell.cas.usf.edu/ pspector/scales/jsspag.html.

[9] McGregor J. (2017). Job satisfaction is up, but still well below one-time highs. Retrieved from https://www.washingtonpost.com/news/on-

leadership/wp/2017/09/01/job-satisfaction-is-up-but-still-wellbelow-one-time-

highs/?noredirect=on\&utm_term=.cf0a $7 \mathrm{fb} 5 \mathrm{f5} \mathrm{a} 2$.

[10] Böckerman, P. and Ilmakunnas, P. (2010). The job satisfaction-productivity nexus: A study using matched survey and register data Retrieved from https:/helda.helsinki.fi/bitstream/handle/10138/17378/thejobs a.pdf? sequence $=1$.

[11] Sharma H. (2011). Predictive Analytics \& Marketing - The next stage of Business Optimization, pp. 25. Retrieved from http://www.optimizesmart.com/introducing-predictivemarketing-stage-business-optimization.

[12] Saunders M., Lewis P. \& Thornhill A. (2009). Research methods for business students fifth edition. Pearson Education, Limited, Edinburgh Gate, Harlow, Essex CM20 2JE England. 462 pp.

[13] Access (2019). Choosing the best trendline for your data. Retrieved from https://support.office.com/enus/article/choosing-the-best-trendline-for-your-data1bb3c9e7-0280-45b5-9ab0-d0c93161daa8.

[14] Joeu, (2004) Use Polynomial Equation to Forecast x values for Known $y$ Values. Retrieved from https://www.mrexcel.com/forum/excel-questions/1010865use-polynomial-equation-forecast-x-values-known-yvalues.html.

[15] George, M. L., Rowlands, D., Price, M. and Maxey, J. (2005), The Lean Six Sigma Pocket Toolbook, McGraw-Hill, USA 85 pp. 